Copyright (C 2015 IEEE. Personal use of this material is permitted. Permission from IEEE must be obtained for all other uses, in any current or future media, including reprinting/republishing this material for advertising or promotional purposes, creating new collective works, for resale or redistribution to servers or lists, or reuse of any copyrighted component of this work in other works. 


\title{
Fuzzy Approach for Online Coordination of Plug-In Electric Vehicle Charging in Smart Grid
}

\author{
Amir S. Masoum, Member IEEE, Sara Deilami, Member, IEEE, \\ A. Abu-Siada, Senior Member, IEEE, Mohammad A.S. Masoum, Senior Member, IEEE
}

\begin{abstract}
This paper proposes an online fuzzy coordination algorithm (OL-FCA) for charging plug-in electric vehicles (PEVs) in smart grid networks that will reduce the total cost of energy generation and the associated grid losses while maintaining network operation criteria such as maximum demand and node voltage profiles within their permissible limits. A recently implemented PEV coordination algorithm based on maximum sensitivity selection (MSS) optimization is improved using fuzzy reasoning. The proposed OL-FCA considers random plug-in of vehicles, time-varying market energy prices and PEV owner preferred charging time zones based on priority selection. Impacts of uncoordinated, MSS and fuzzy coordinated charging on total cost, gird losses and voltage profiles are investigated by simulating different PEV penetration levels on a 449-node network with three wind distributed generation (WDG) systems. The main advantage of OL-FCA compared with the MSS PEV coordination is the reduction in the total cost it introduces within the 24 hours.
\end{abstract}

Index Terms- Plug-in electric vehicles, online PEV coordination, fuzzy, load management and smart grid.

\section{INTRODUCTION}

$\mathrm{S}_{\mathrm{r}}^{\mathrm{N}}$ MART GRID (SG) technologies are currently undergoing rapid developments to modernize legacy power grids and to cope with the future increasing energy demands. Most electric power utilities are moving toward smarter solutions for generation, distribution and control of the grid. On the other hand, end users are also becoming more concern about their environments and are willing to adjust their life style and perhaps pay higher electricity bills to promote pollution free renewable energy resources and efficient smart appliances. It is expected that plug-in electric vehicles (PEVs) dominate the market in the near future as pollution-free alternatives to conventional petroleum based transportations. References [1-3] provide extensive reviews on smart grid, PEV impacts and coordination strategies. In general, PEVs connected to smart grids can operate in charge or discharge modes with the energy being transferred from grid to vehicle (G2V) or from vehicle to grid (V2G), respectively. The research on PEVs has been mainly focused on their impacts [4-6], G2V [7-20] and V2G operations [3, 21-24].

Recent research indicates that uncoordinated (random) PEV charging at high penetration levels will have detrimental

A.S. Masoum is with Operational Asset Management, Western Power, WA, Australia, S. Deilami, A. Abu-Siada and M.A.S. Masoum are with the Department of Electrical and Computer Engineering, Curtin University, WA, Australia. Emails: a_masoum@ieee.org, s.deilami@curtin.edu.au, a.abusiada @curtin.edu.au, and m.masoum@curtin.edu.au. impacts on grid performance and efficiency [1-6]. To overcome these problems, the utilities can either force coordinated PEV charging or motivate their consumers to shift their PEV charging loads to off-peak hours. Motivations can be initiated by educating PEV owners, offering price incentives for off-peak hours charging and implementing dynamic energy prices. To date, most proposed PEV coordination approaches [7-20] are not suitable for online applications as they are either based on forecasted PEV charging demand or require significant computing times when system size and/or vehicle penetration levels increase. Strategies for PEV charge coordination are generally divided into decentralized (distributed) and centralized categories [7]. With decentralized coordination strategies, individual PEV owners have authority to make decision about the time and rate of their own vehicle charging. While this approach offers significant ownership authority to the PEV owners; it may not ensure global optimal charging outcomes from the gird point of view in terms of system losses, voltage profile, overloading and security [7-8]. This is mainly due to the fact that the aggregator or system operator does not have a direct control over the widespread PEV charging activities and can only offer energy price incentives through dynamic pricing in order to shift charging tasks to valleys of the load profile. With the centralized coordination strategies, the aggregator acts as an interface between PEV owners and the system operator to provide charging services considering benefits of both parties by making decisions about the time and rate of all PEV charging in order to achieve an overall optimal solution [7-10]. The aggregator relies on the smart grid facilities such as smart meters for real-time updating of PEV load status such as vehicle arrival and desired departure times, battery state of charge (SOC), etc. The coordination can be based on dynamic or static charging. In centralized dynamic charging, PEVs can be plugged in/out at any time and the aggregator keeps updating the load profile and finding new schedule while static charging requires PEV owners to submit their schedule in advance. Dynamic charging offers more flexibility for PEV owners; however, it is more complicated and requires more computing time.

Reference [6] investigates the impacts of coordinated PEV charging using deterministic and stochastic dynamic programing; however, the approach is not suitable for online PEV coordination as the user priorities/preferences are not included and the operational constraints such as node voltage magnitudes are not being directly involved. References [1112] implement a real-time (on-line) PEV coordination 
algorithm based on maximum sensitivity selection (MSS) optimization to reduce grid losses and perform peak load saving considering random plug-in (arrival) of the vehicles. Reference [12] proposes an operating framework for aggregators of PEVs and also designs a minimum-cost load scheduling algorithm; however, the approach is based on the forecast electricity price and PEV power demands. Reference [14] presents vehicle usage data for 76 vehicles in a one-year period and predicts PEV charging profiles and electrical range reliability. Reference [9] proposes a PEV charging that will optimize aggregator's revenue, as well as customer demand and cost. In [15], a dynamic aggregator is proposed to optimize cost of PEV charging. In [8], a three-step approach is used for demand side management of PEVs. References [16] and [17] present centralize and iterative decentralized PEV charging algorithms that will smooth the daily load curve, respectively. References [9] and [18] propose optimal PEV charging coordination in day-ahead electricity market environment considering energy storage as ancillary services and V2G services, respectively. References [11-12, 19-20] also consider voltage quality in the PEV coordination problem.

In references [3, 21-25], PEVs are operated in V2G modes to support smart grid through ancillary frequency regulation and energy storage services. The substantial grid energy requirements for PEV charging at high penetration levels can be partially supplied through PV and wind distributed generation (DG) systems. This may prove to be beneficial considering the intermittency of renewable DGs and possibility of charging PEVs during peak generation hours. However, there are limited publications on PEV coordination with DG resources [24-25].

This paper proposes an online fuzzy coordination algorithm (OL-FCA) for charging PEVs that reduces total cost of energy generation and grid losses while considering random plug-in of vehicles, time-varying market energy prices, consumer preferred charging time zones, node voltage profiles and maximum demand (generation) limits. The impacts of MSS [11-12] and fuzzy PEV coordination charging on cost, grid losses, voltage profiles and distribution transformer loading are investigated by simulating a 449-node system consisting of the IEEE $23 \mathrm{kV}$ distribution system connected to 22 low voltage $415 \mathrm{~V}$ residential networks populated with PEVs without/with three wind distributed generations (WDGs).

\section{Problem Formulation}

The PEV charging coordination (G2V) can formulated as a nonlinear cost minimization problem with the following objective function and constraints [12]:

$$
\begin{aligned}
\min F_{\text {cost }}= & F_{\text {cost-loss }}+F_{\text {cost-gen }}=\sum_{t} K_{E} P_{t, \text { loss }} \\
& +\sum_{t} K_{t, G} D_{t, \text { total }}, \quad t=\Delta t, 2 \Delta t, \ldots .24 \text { hours }
\end{aligned}
$$

where $P_{t, l o s s}=\sum_{k=0}^{n-1} R_{k, k+1}\left(\left|V_{k+1}-V_{k} \| y_{k, k+1}\right|\right)^{2}$.

Subject to:

$\Delta V_{k}=V_{k}-V_{\text {rated }} \leq \Delta V_{\text {max }}$, for $k=1, \ldots, n$

$D_{t, \text { total }}=\sum_{k} P_{t, k}^{\text {load }} \leq D_{t, \text { max }}$

where $F_{\text {cost-loss }}$ and $F_{\text {cost-gen }}$ are the costs corresponding to total system losses and total generation, respectively. $\Delta t=5 \mathrm{~min}$ is the time interval; $K_{E}=50 \$ / \mathrm{MWh}$ [12] and $K_{\Delta t, G}$ (Fig.1) are the costs per MWh of losses and generation, respectively; while $k$ and $n$ are the node number and total number of nodes. $\Delta V_{k}$ is the per unit (pu) voltage deviation of bus $k$ which is limited to $\Delta V_{\max }=0.1 \mathrm{pu}$ in this paper. $D_{t, \max }$ is the maximum demand level at $t=\Delta t$ that can be set to the maximum demand without any PEVs.

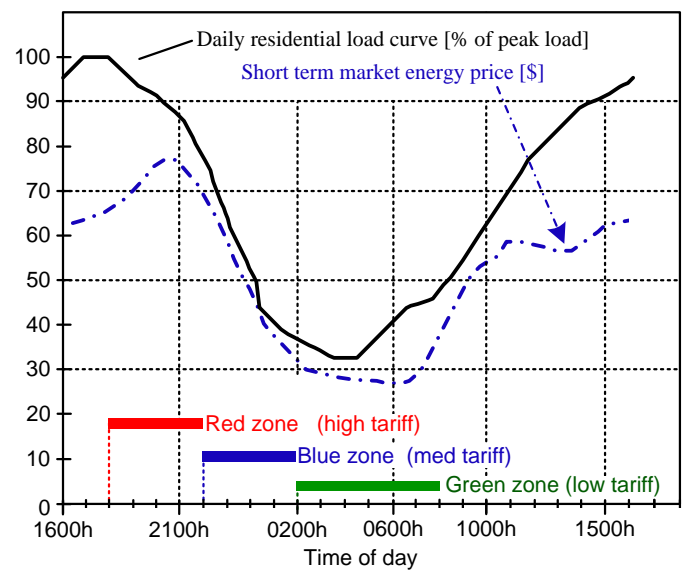

Fig. 1. Daily residential load curve, variable short term market energy pricing and subscription options of charging time zones for PEV owners [12].

\section{Proposed Online Fuzzy CoOrdination Algorithm (OL-FCA) FOR PEV CHARGING}

As an alternative to random charging of PEV batteries, this paper takes advantage of the sophisticated smart grid communication backbone and implements an online fuzzy coordination algorithm (OL-FCA) that will improve grid performance and reliability by taking charge controls out of the owners' hand and automatically coordinate PEVs. A recent PEV coordination algorithm based on MSS optimization [11-12] will be improved using fuzzy reasoning.

\section{A. Minimization of Objective Function (Cost)}

For online minimization of the cost function, the fast and relatively accurate MSS optimization approach is used to quantify the objective function sensitivity (system losses) to PEV charging loads at a given time step [12, 26]:

$$
M S S_{t, j}=\partial P_{t, l o s s} / \partial P_{P E V, j}, \quad j=1, \ldots ., j_{m}
$$

where $M S S_{t, j}$ is the sensitivity of system losses to PEV charging at node $j$ at time interval $t$ and $j_{m}$ is the total number of PEVs while $P_{P E V, j}$ is the power consumption of the PEV connected to node $j$. Entries of the MSS vector are readily deduced from the Jacobian matrix of the load flow $[12,26]$. 


\section{B. Fuzzification of Constraints}

Fuzzy reasoning is used to incorporate the PEV coordination constraints and to select the most suitable PEVs for charging at each time interval $t$. For the sensitivities of constraints and losses $\left(\Delta V_{k}, P_{\text {loss,rated }}, D_{t, \max }\right.$ in Eqs.1-3) with respect to PEV charging at each bus, the fuzz membership functions of Figs.2(a)-(c) are used. In addition, the time-dependent weighting factors of Fig.2(d) are included in the maximum demand membership function to assure consumer satisfaction and full charge of all batteries by 6am.

- Fuzzification of Voltage Deviations $\left(\Delta V_{k}\right)$ - For the deviation of voltage constraints with respect to PEV charging at bus $k$, the exponential membership function $\mu_{\Delta V k}$ of Fig.2(a) is used. $\Delta V_{0}=\Delta V_{\max } / 2$ corresponds to Eq.2 such that buses with voltage deviations less than this limit have full set memberships. Therefore, a bus with high voltage deviation is given a low membership value:

$$
\mu_{\Delta V_{k}}=\left\{\begin{array}{ll}
1 & \text { if } \Delta V_{k} \leq \Delta V_{0}, \\
e^{-\left(\Delta V_{k}-\Delta V_{0}\right) / T_{V}} & \text { if } \Delta V_{k}>\Delta V_{0},
\end{array} \quad k=1, \ldots, n\right.
$$

- where $\Delta V_{0}=0.05 \mathrm{pu}$ and the time constant is set to $T_{V}=0.034$ such that $\mu_{\Delta V k}=0.23$ for $\Delta V_{k}=\Delta V_{\max }=0.1$ pu (Eq. 2).

- Fuzzification of System Losses ( $P_{t, \text { loss }}$ )- To limit total system power losses due to PEV charging, the exponential membership function of Fig.2(b) is used. The time constant should be adjusted such that PEV charging at time interval $t$ result in system losses less than the rated losses $P_{\text {loss,rated }}$ (e.g., highest losses within 24 hours without any PEV charging) have high membership values. This can occur at low levels of the daily load curve during early morning hours (Fig.1). Therefore, PEV charging scenarios with high losses are given low membership values:

$\mu_{\text {loss }}=e^{-P_{t, l o s s} / T_{\text {loss }}}$

where the time constant is set to $T_{\text {loss }}=0.034$ such that $\mu_{\text {loss }}=0.5$ for total losses equal to the rated losses without any PEV charging $P_{t, \text { loss }}=P_{\text {loss, rated }}$ (Eq. 1 ).

- Fuzzification of Maximum Demand Level $\left(D_{t, \max }\right)$ - Two exponential membership functions with different time constants are used to limit maximum total demand during PEV charging periods as shown in Fig.2(c):

$\mu_{D}=\left\{\begin{array}{l}e^{-\Delta D / T_{D+}} \text { if } \Delta D=D_{t, \text { total }}-W_{D} D_{t, \text { max }} \geq 0 \\ e^{+\Delta D / T_{D-}} \text { if } \Delta D=D_{t, \text { total }}-W_{D} D_{t, \text { max }}<0\end{array}\right.$

where $W_{D}$ is the maximum demand weight factor that will be adjusted based on the vehicle waiting time in the PEV Queue Table (Fig.2(d)). The time constant $T_{D^{+}}$should be much smaller than time constant $T_{D \text { - }}$ to strictly prevent total system demands beyond the designated maximum value of $D_{t, \max }$ under all PEV charging conditions. This will also prevent possible line and transformer overloading. In this paper, $T_{D^{+}}=0.0125$ and $T_{D-}=0.125$.
- Maximum Demand Weight Factors Based on PEV Waiting Time in the Queue Table- An important feature of OL-FCA is to perform coordination such that on one side vehicle charging are postponed to off-peak hours (to reduce cost of generating energy) and on the other side PEVs are charged as quickly as possible to assure consumer satisfaction and full charge of all batteries by $6 \mathrm{am}$. To implement this, the weight factor $W_{D}$ of Eq.7 is adjusted according to the designated red, blue, and green time zones (Fig.2(d)).

OL-FCA keeps track of all charging activities by continuously storing and sorting vehicle information (priorities, locations, plug-in and plug-out times) in the PEV Queue Table. However as the approach is online, at each time interval $\Delta t$, there are no information about the numbers and requested charging time zones of the incoming PEVs arriving at later hours; therefore, $W_{D}$ is linearly increased according to the vehicle waiting time in the Queue Table (particularly for the green time zone), as shown in Fig.2(d). Note that the slop of $W_{D}$ functions increase with time. That is the slop of the green zone (2$6 \mathrm{am})$ is much larger than the slop of the red zone (6-10pm) to assure full charge of all batteries by $6 a m$.

\section{Fuzzy Combination of Membership Functions}

The additive or multiplicative generators of a t-norm can be used to combine fuzzy membership functions [27]. In this paper, the algebraic sum of the weighted membership functions is used to combine the fuzzy constraints:

$\mu_{P E V, j}=0.3 \mu_{\Delta V_{k}}+0.3 \mu_{\text {loss }}+0.4 \mu_{D}, \quad j=1, \ldots ., j_{m}$

where $0.3,0.3$ and 0.4 are the selected weighting factors for voltage deviation, system loss and maximum demand membership functions, respectively. At each time interval $t$, the decision on whether to start or defer the charging of a vehicle will depend on its membership function as well as its ranking in the PEV Queue Table (Eq.4).

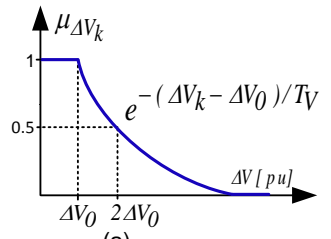

(a)

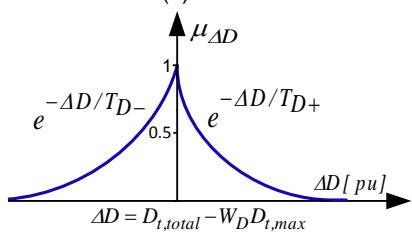

(c)

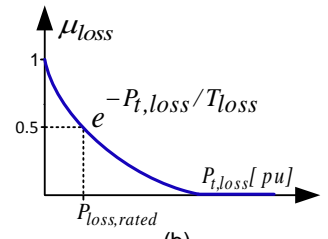

(b)

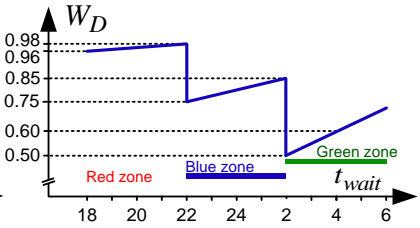

(d)
Fig. 2. Proposed membership functions for; (a) voltage deviations (Eqs.2 and 5), (b) total system losses (Eqs.1 and 6), (c) maximum demand level (Eqs.3 and 7), (d) maximum demand weighting factor (Eq.7).

\section{Flow Chart of OL-FCA}

The proposed online algorithm (Fig.3) begins by reading input parameters and initializing variables. At each time step 
( $t=\Delta t, 2 \Delta t, 3 \Delta t, \ldots . .24$ hours ), OL-FCA will:

- Sample the current state of the grid (e.g., runs load flow to calculate load levels, node voltages, system losses, etc.).

- Update $D_{t, \max }$ and DG status; compute MSS vectors and add randomly arriving PEVs to "PEV Queue Table". The queue also contains PEVs from previous time steps that have not been charged due to a constraint violation.

- Sort Queue Table from high to low priority based on the PEV time zones (red, blue, green) and sensitivities (Eq.4).

- Compute (starting with the PEV at the top of Queue Table) PEV fuzzy membership function (Eq.9) and decide to either activate or delay (until next $t$ ) vehicle charging.

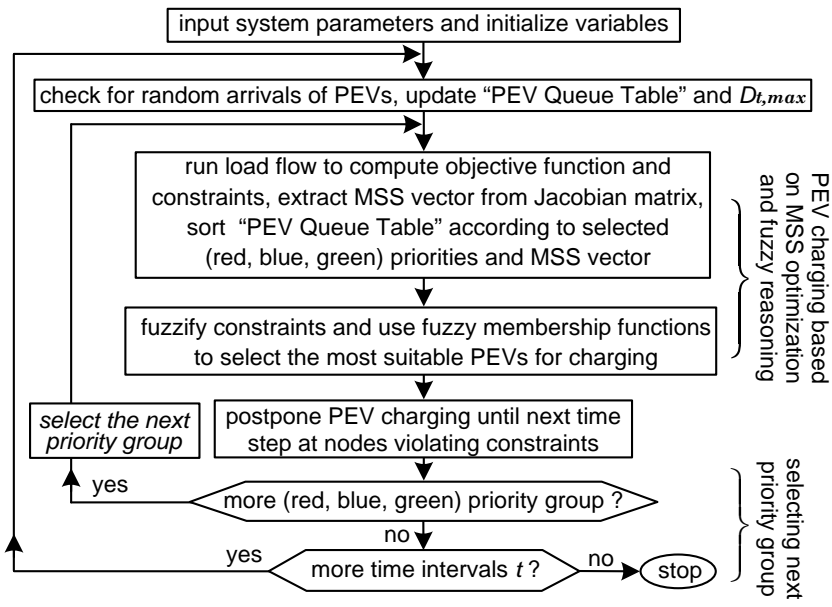

Fig. 3. Proposed OL-FCA for online PEV charging coordination with random arrivals of vehicles at each time interval considering system losses, voltage profiles and maximum demand levels.

\section{The 449 Node SMART GRID TEST SySTEM}

The smart grid test system topology of Fig.5(a) is used to evaluate OL-FCA and compare its performance with the MSS PEV coordination approach of [12]. It consists of the IEEE 31 bus $23 \mathrm{kV}$ distribution test system connected with 22 low voltage $415 \mathrm{~V}$ residential feeders. In addition, OL-FCA performance will also be demonstrated with 3 WDG units connected to nodes 4, 7 and 12. Each residential feeder consists of 19 nodes representing customer households with randomly assigned priorities and charging time zone (Fig.5(b)). System data including line, residential load (2kW at 0.9 lagging power factor), transformer, PEV battery (10kWh, 70\% depth of discharge), PEV charger (88\% efficiency, fixed charging power of $4 \mathrm{~kW}$ requiring $8 \mathrm{kWh}$ of energy from grid to charge a single PEV) parameters are available in [12].

\section{Simulation RESUlts AND DisCUSSIONS}

Simulations are performed on the smart grid system of Fig.5 considering eight PEV charging scenarios (Table I). Simulation results with time interval of $\Delta t=5 \mathrm{~min}$ for $\mathrm{PEV}$ penetration levels of $16 \%, 32 \%, 47 \%$ and $63 \%$ without/with three WDGs are presented in Figs.6-9 and Tables II-III.
TABLE I

PEV CHARGING SCENARIOS FOR SMART GRID SYSTEM OF FIG.5 WITH WDGS (FIG.4) CONSIDERING DAILY LOAD CURVE, ENERGY PRICING, AND PEV CHARGING TIME ZONES OF FIG.1.

\begin{tabular}{|c|l|}
\hline Case & Operating Conditions and PEV Coordination \\
\hline A & Uncoordinated (random) PEV charging \\
\hline B & MSS PEV coordination [12] \\
\hline C & OL-FCA (fuzzy PEV coordination; Fig.3) \\
\hline D & MSS PEV coordination with WDGs (3x5=15\% penetration) \\
\hline E & OL-FCA with WDGs (3x5=15\% penetration) \\
\hline F & Impacts of WDG peak generation time on OL-FCA \\
\hline G & Impacts of WDG penetration on OL-FCA \\
\hline H & Impacts of WDG location on OL-FCA \\
\hline
\end{tabular}

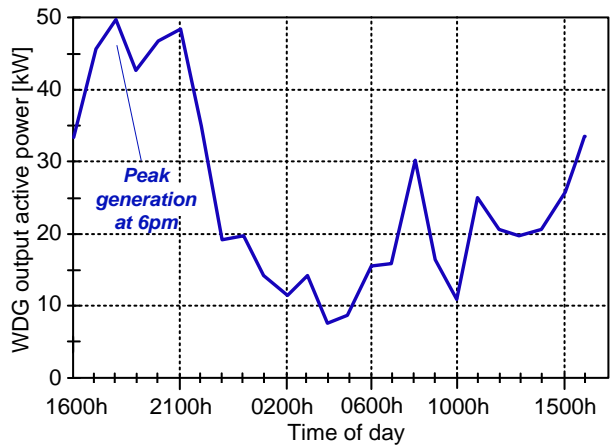

Fig. 4. WDG active output power characteristic with peak generation of $50 \mathrm{~kW}$ at 6pm (based on scaled down actual recordings from Walkway wind farm, WA, Australia on July 7, 2012).

\section{A. Uncoordinated PEV Charging (Case A)}

To investigate the impacts of uncoordinated charging on the grid, a realistic charging scenario is simulated with vehicles being randomly plugged in during early evening hours (1800h-2200h). Simulation results are summarized in Table II (rows 4-8) and plots of system power consumption, voltage profile of the worst effected bus and system power losses are shown in Figs.6(a), 8(a), and 9(a), respectively. As expected, there are significant increases in power demand, power generation, voltage deviations and power losses even at low PEV penetrations. For example, total cost is increased by $30 \%$ for $\mathrm{PEV}$ penetration of $16 \%$. The system is also experiencing extensive voltage drops beyond the accepted limit of 0.9pu at higher PEV penetration levels (Fig.8(a)).

\section{B. MSS Coordinated PEV Charging (Case B)}

The MSS based PEV coordination algorithm of [12] is simulated and results are presented in Table II (rows 9-13), Figs.6(b), 8(b), and 9(b). A general improvement in system performance including reduction in total costs is observed while all node voltages are regulated within permissible lower (0.9pu) and upper (1.1pu) limits even at high PEV penetration level of $47 \%$ and $63 \%$ as reported in [12].

\section{Fuzzy Coordinated (OL-FCA) PEV Charging (Case C)}

The proposed OL-FCA of Fig. 3 is implemented and results are presented in Table II (rows 14-18), Figs.6(c), 7, 8(c) and 9(c). There is significant improvement in system operation and performance compared with both the uncoordinated and MSS coordinated charging of Cases A-B. For example, there 
is a considerable improvement in the percentage increase of total cost (Table II, column 6) with 63\% PEV penetration from 59\% (uncoordinated charging) and 15.24\% (MSS charging) to $12.7 \%$ while keeping node voltage profiles and maximum demand level within the permissible limits. Unlike MSS coordination, OL-FCA is designed to allow small deviations/violations of (voltage and/or maximum demand) constraints according to the corresponding member functions of Fig. 2 to limit losses and reduce cost of generating energy.

\section{MSS and Fuzzy Coordination with WDGs (Cases D-E)}

Both MSS and OL-FCA can accommodate DG resources by treating them as PQ nodes injecting power into the grid. To demonstrate possible DG participations and contributions in PEV charging, three WDGs (with peak output power of $50 \mathrm{~kW}$ at $6 \mathrm{pm}$, Fig.4) are connected at nodes 4, 7 and 12 as shown in Fig.5. This will represent a total wind penetration of $3 \times 5=15 \%$. Simulation results for MSS and fuzzy coordination with 63\% PEV penetration are presented in Table II (rows 19-28) and Figs.10(a) and (b), respectively. Results show that WDGs will further enhance the overall performance of the system in terms of reducing voltage deviation, system losses and total cost at all PEV penetration levels. Note that MSS coordination utilizes the entire available WDG output power at each time interval to charge as many (red, blue and green)
PEVs as possible during the peak load hours (Fig.10(a), 1700h-2200h). The problem with this simple approach is in reducing the possibility of serving high priority (red) vehicles that may shortly arrive within the next few time intervals. Therefore, OL-FCA prefers to use WDG output during peak hours to only charge the high priority (red) vehicles (Fig.10(b), 1700h-2000h). This will also have the advantage of reducing transform loadings during peak load hours (Fig.11).

\section{E. Impact of WDG Peak Generation Time (Case F)}

Due to the stochastic nature and behavior of WDGs, their peak generation times and duration will randomly change within the 24 hours and may not always coincide with the residential peak load hours as shown in Fig.2. To demonstrate impact of WDG peak generation time on PEV coordination, Case $C$ is repeated with shifted WDG peak time from $6 \mathrm{pm}$ to $8 \mathrm{pm}, 10 \mathrm{pm}$ and $12 \mathrm{pm}$. WDG have the potential to reduce total losses and total cost, as well as the burden on the power transformers. Fig. 11 shows impacts of WDG peak generation time on distribution transformer loading. As expected, there is more reduction in transformer loading when the peak WDG durations occur during early evening peak load hours (e/g., 6pm, 8pm) with sustainable PEV charging activities.

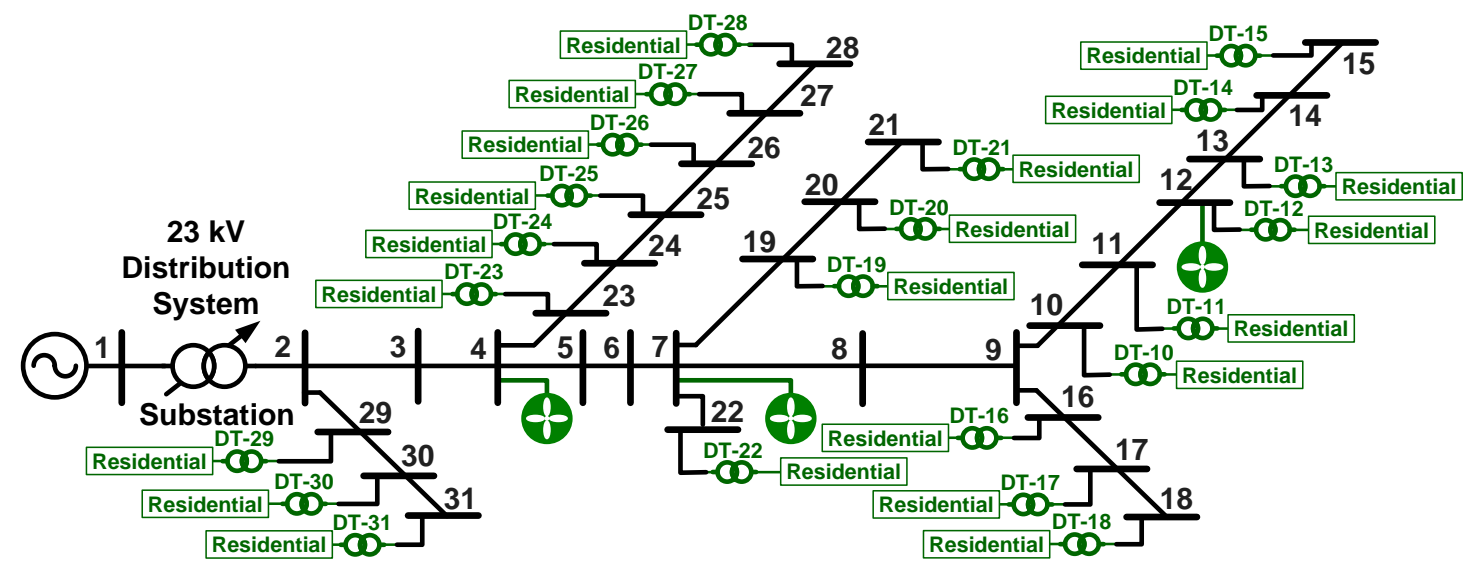

(a)
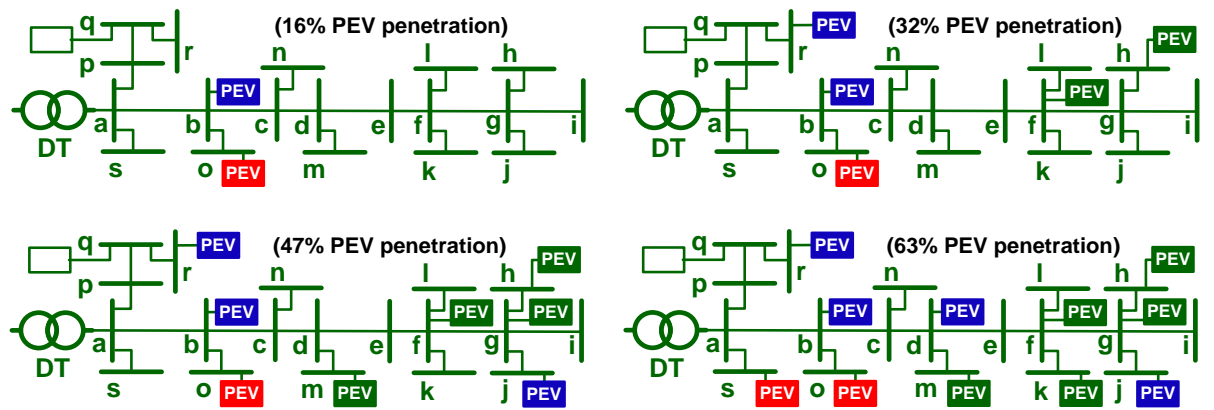

(b)

Fig. 5. The 449 node smart grid topology consisting of the IEEE 31 node $23 \mathrm{kV}$ system with $3 \mathrm{WDG}$ units and 22 low voltage 19 node $415 \mathrm{~V}$ residential feeders; (a) system diagram, (b) detailed diagram of one $415 \mathrm{~V}$ residential feeder with $16 \%$, 32\%, 47\% and 63\% PEV penetration showing high, medium and low priority consumers in red, blue and green colours paying very high, moderate and very cheap tariff rates, respectively. 


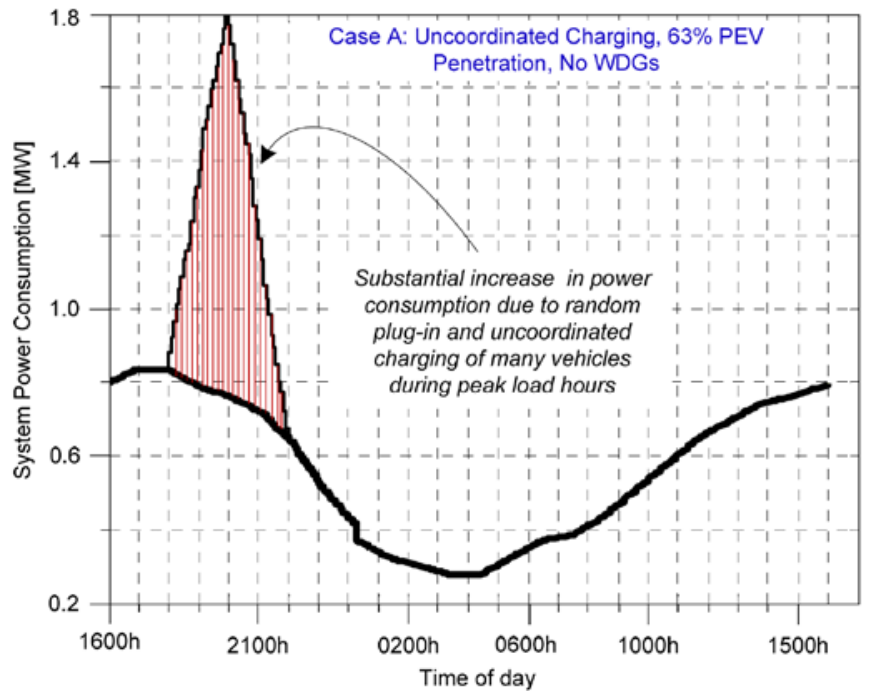

(a)

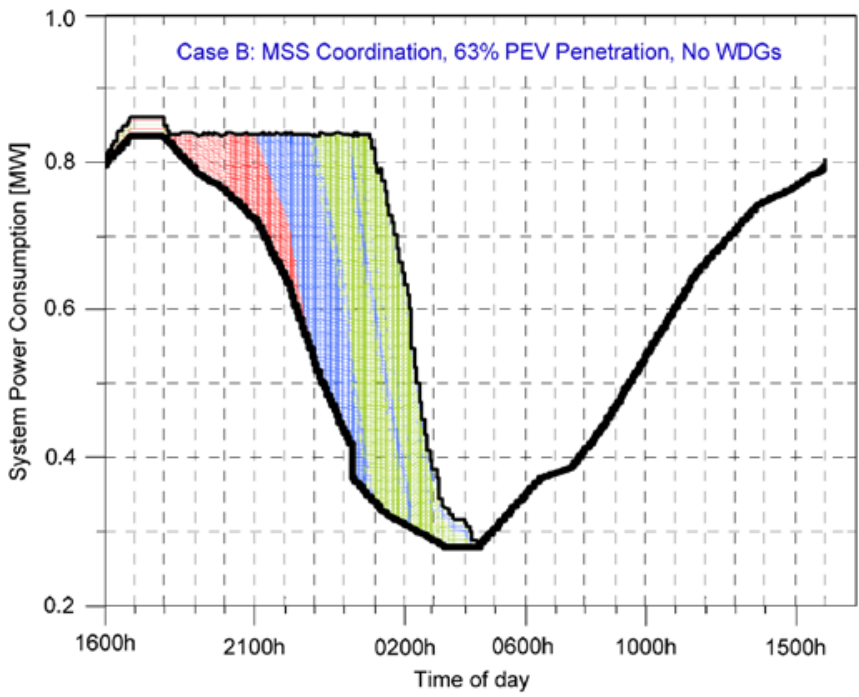

(b)

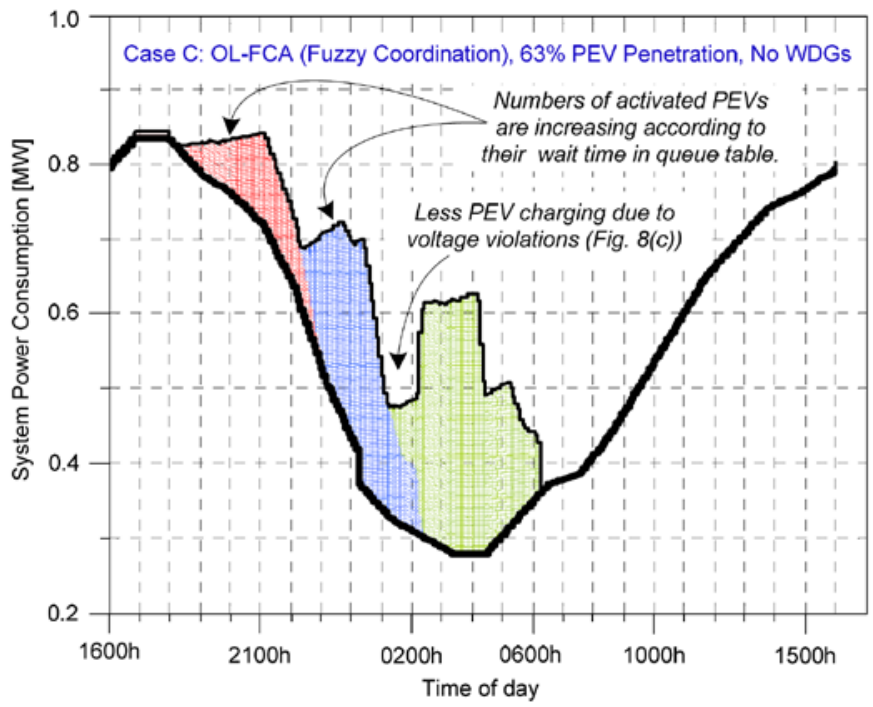

(c)

Fig. 6. System power consumption of 449 node smart grid (Fig.5) with $63 \%$ PEV penetration for; (a) Case A, (b) Case B, (c) Case C (Tables I, II).

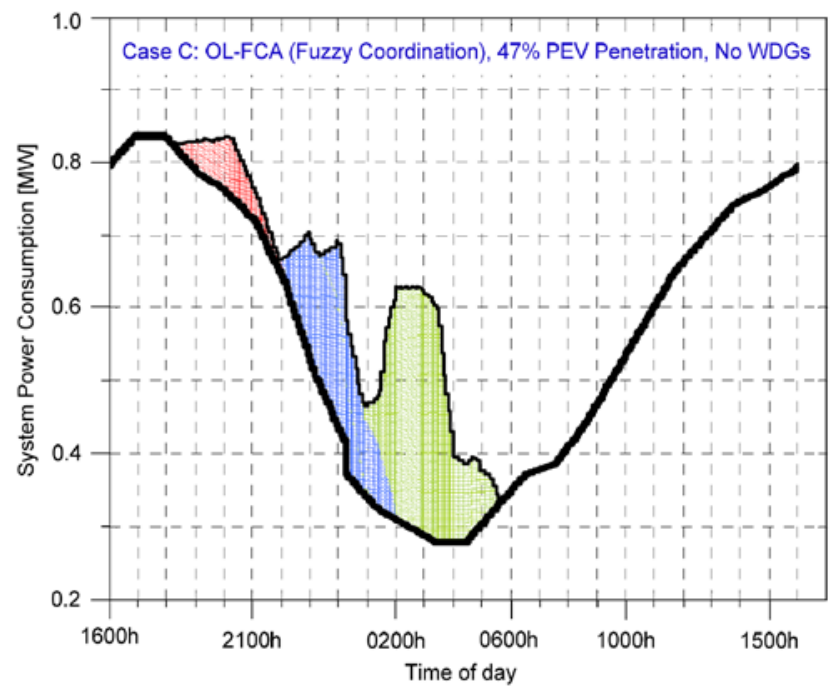

(a)

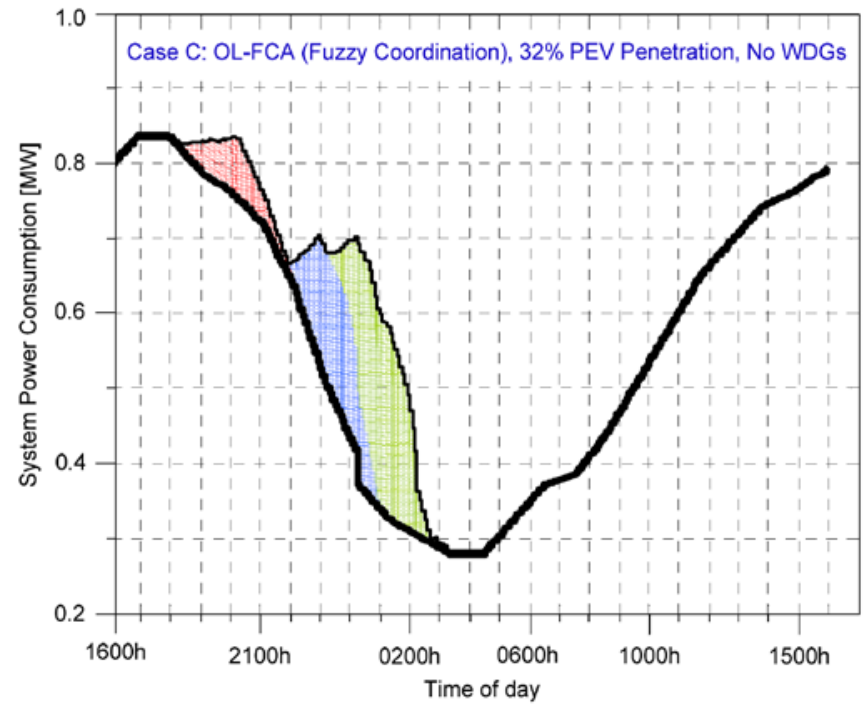

(b)

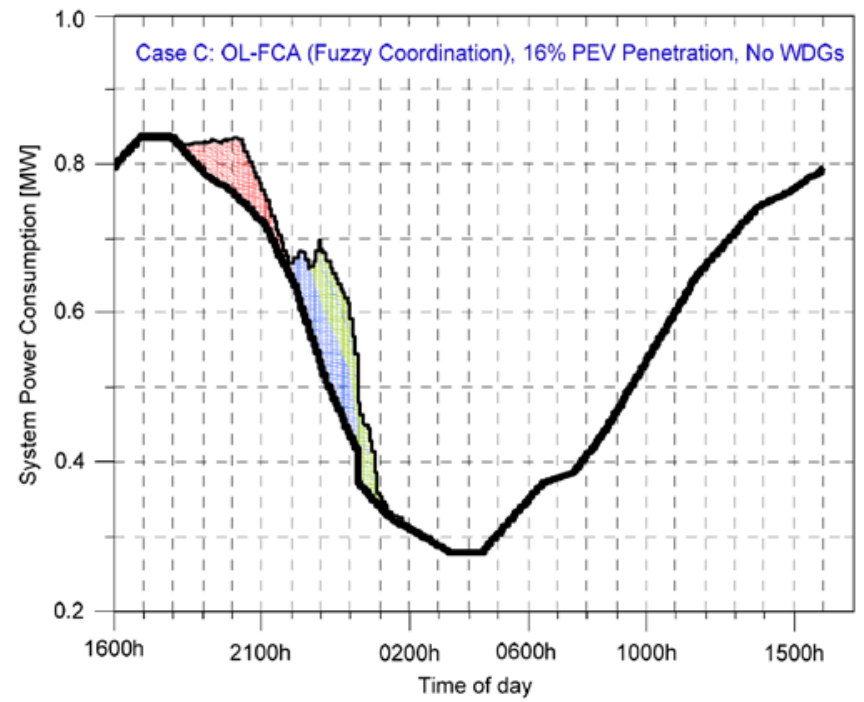

(c)

Fig. 7. System power consumption for Case C (OL-FCA) with PEV penetration levels of; (a) $47 \%$, (b) $32 \%$, (c) $16 \%$. 


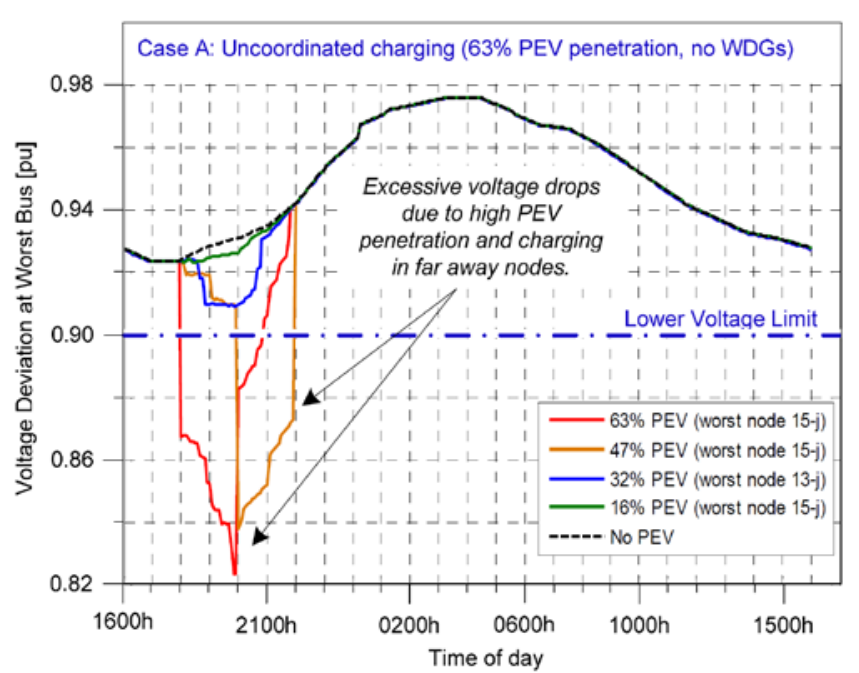

(a)

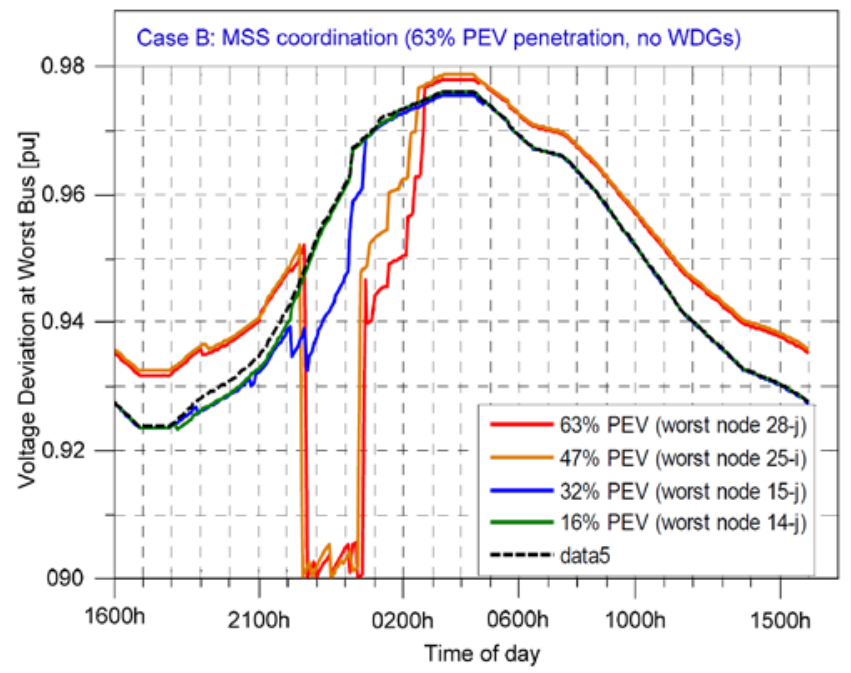

(b)

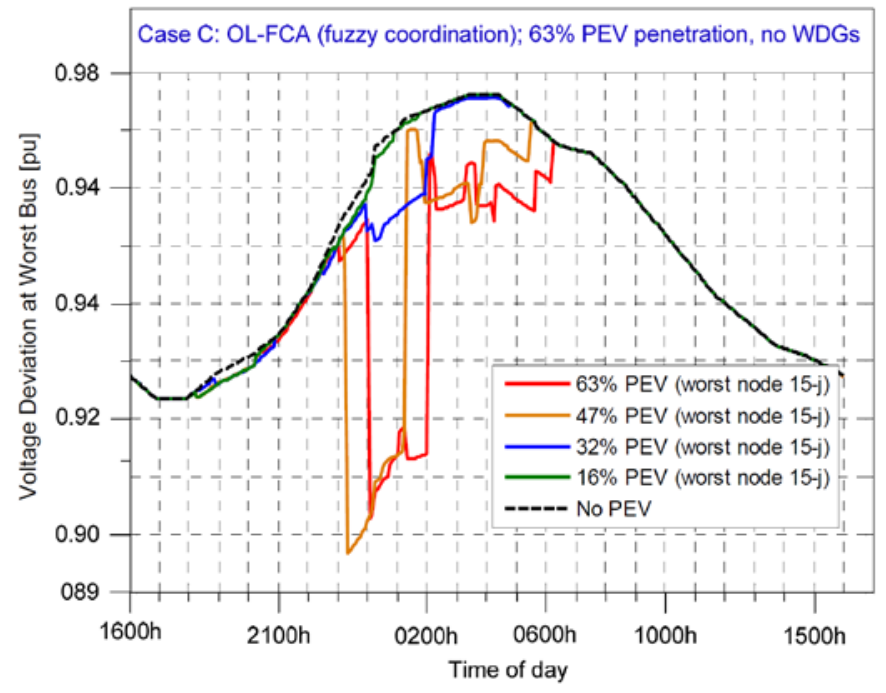

(c)

Fig. 8. Voltage profile (for the worst affected nodes) of the 449 node smart grid (Fig.5) for; (a) Case A, (b) Case B, (c) Case C (Table I).

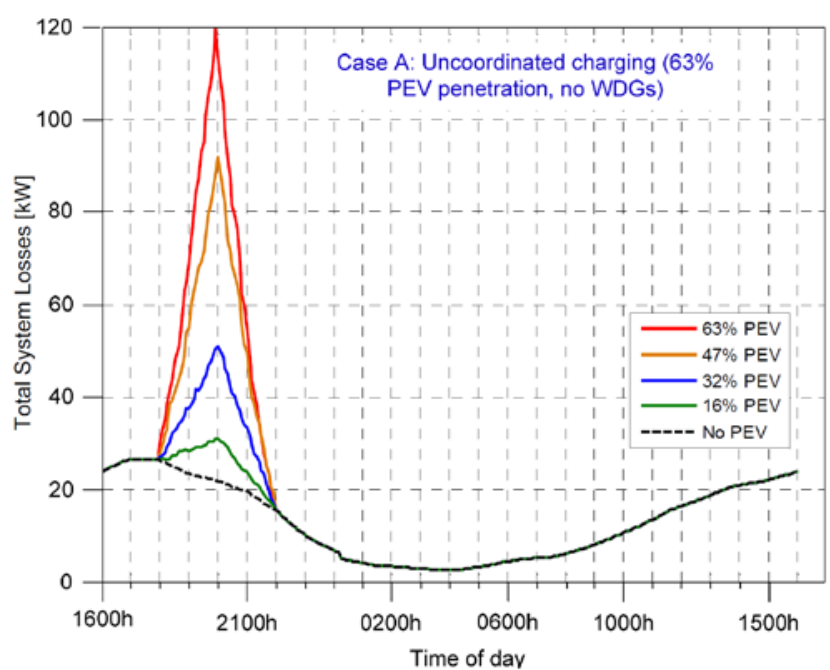

(a)

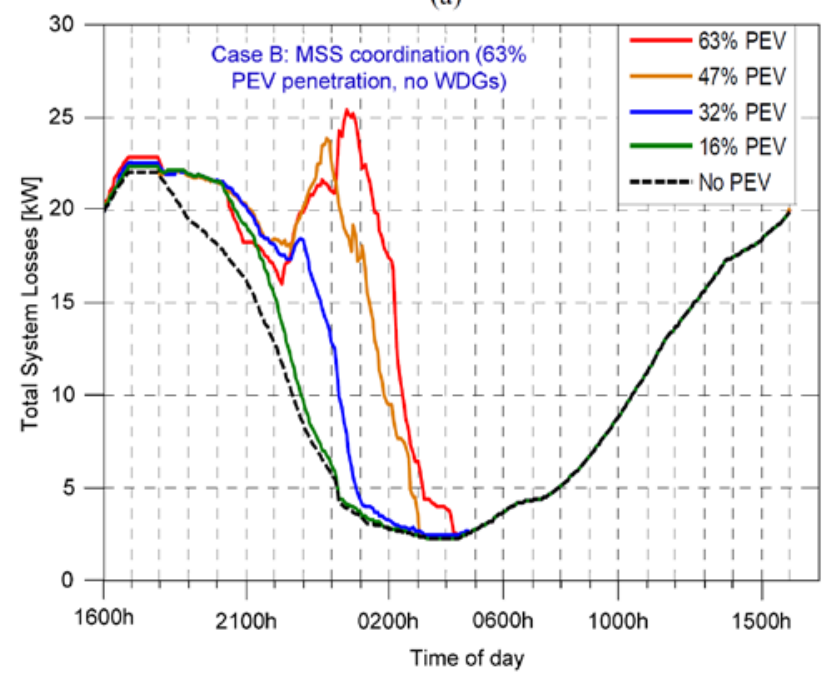

(b)

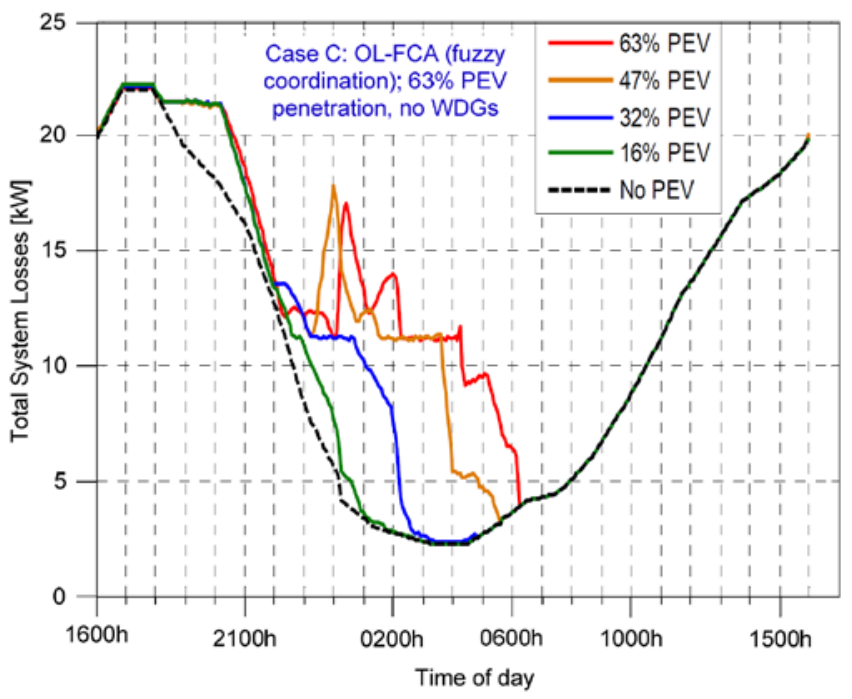

(c)

Fig. 9. Total system power losses of the 449 node smart grid (Fig.5) for; (a) Case A, (b) Case B, (c) Case C (Table I). 


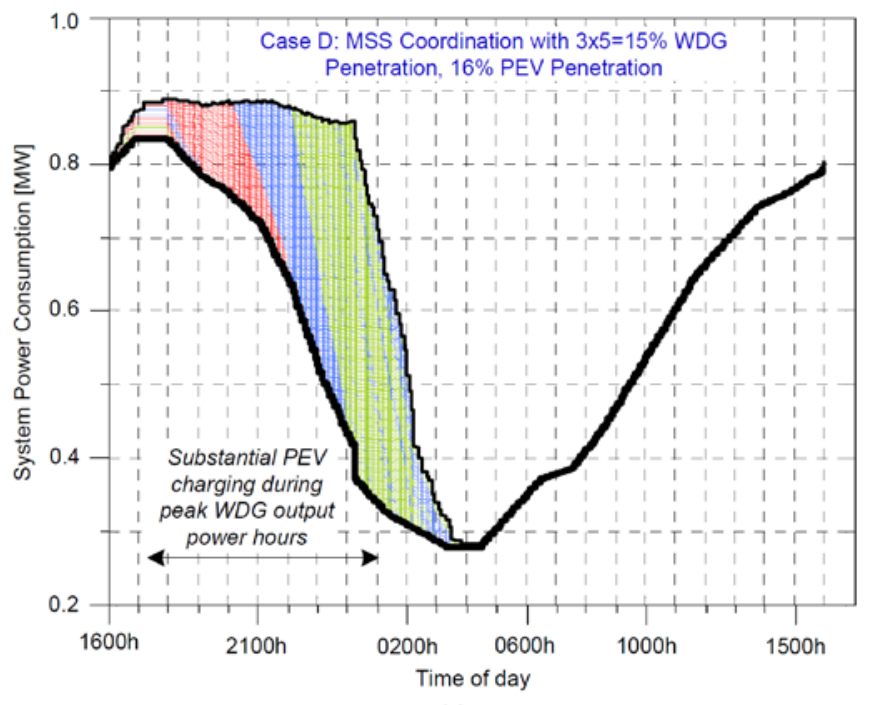

(a)

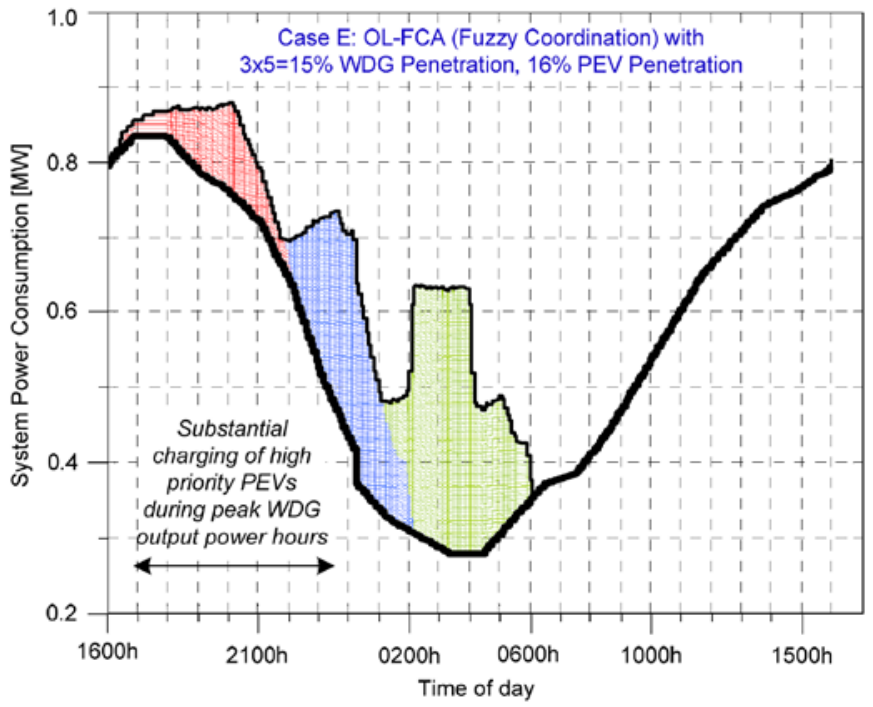

(b)

Fig. 10. System power consumption with $3 \times 5=15 \%$ WDG penetration; (a) Case D (MSS coordination), (b) Case E (OL-FCA).

\section{F. Impact of WDG Penetration (Case G)}

The sizes of the three WDGs (Fig.5) are adjusted to examine six wind penetration levels of $5,15,10,20,30$, and 40 . Simulation results with OL-FCA coordination for 63\% PEV penetration are summarized in Table III and Fig.12. According to these results, increasing WDGs penetration will substantially reduce system losses, generation cost and transformer loading.

\section{G. Impact of WDG Location (Case H)}

To investigate impacts of wind location, one large $21 \mathrm{~kW}$ WDG unit is considered and connected at different nodes. The calculated total system losses with PEV penetration of 63\% are plotted in Fig.13. As expected, the most appropriate locations of WDGs are toward the end of the HV network on nodes 11-15.
TABLE II

IMPACT OF UNCOORDINATED, MSS [12] AND FUZZY COORDINATED PEV CHARGING ON SMART GRID SYSTEM OF FIG.5. FOR COMPARISON, THE SAME GAUSSIAN RANDOM PEV DISTRIBUTIONS AND PLUG-IN TIMES ARE USED.

\begin{tabular}{|c|c|c|c|c|c|}
\hline $\begin{array}{l}\text { PEV } \\
{[\%]} \\
\end{array}$ & $\begin{array}{c}\Delta V \\
{[\%]} \\
\end{array}$ & $\begin{array}{l}\boldsymbol{I}_{M A X} \\
{[\%]} \\
\end{array}$ & $\begin{array}{c}\begin{array}{c}\text { Generation } \\
\text { cost* [\$/day] }\end{array} \\
\end{array}$ & $\begin{array}{c}\text { Total cost (Eq.1) } \\
{[\$ / \text { day] }}\end{array}$ & \begin{tabular}{|c} 
Increase in Total \\
cost $[\%]^{* *}$
\end{tabular} \\
\hline \multicolumn{6}{|c|}{ Nominal Operation without any PEVs or WDGs } \\
\hline 0 & 7.646 & 0.147 & 770.3 & 786.2 & 0 \\
\hline \multicolumn{6}{|c|}{ Case A: Uncoordinated PEV; Figs.6(a),8(a),9(a) } \\
\hline 16 & 7.69 & 0.179 & 829 & 1,030 & 31.10 \\
\hline 32 & 9.05 & 0.218 & 871 & 1,090 & 38.67 \\
\hline 47 & 16.20 & 0.263 & 916 & 1,180 & 50.10 \\
\hline 63 & 17.60 & 0.307 & 958 & 1,250 & 59.0 \\
\hline \multicolumn{6}{|c|}{ Case B: MSS Coordination [12]; Figs.6(b),8(b),9(b) } \\
\hline 16 & 7.67 & 0.161 & 808 & 825 & 4.93 \\
\hline 32 & 7.66 & 0.167 & 841 & 858 & 9.12 \\
\hline 47 & 10.00 & 0.163 & 865 & 884 & 12.44 \\
\hline 63 & 10.00 & 0.172 & 886 & 906 & 15.24 \\
\hline \multicolumn{6}{|c|}{ Case C: OL-FCA; Figs.6(c),7,8(c),9(c) } \\
\hline 16 & 7.65 & 0.159 & 805 & 821 & 4.42 \\
\hline 32 & 7.65 & 0.158 & 828 & 845 & 7.48 \\
\hline 47 & 10.32 & 0.160 & 842 & 861 & 9.51 \\
\hline 63 & 9.72 & 0.159 & 866 & 886 & 12.70 \\
\hline \multicolumn{6}{|c|}{ Case D: MSS Coordination with (15\% penetration) WDGs; Fig.10(a) } \\
\hline 16 & 7.66 & 0.177 & 717 & 733 & -6.76 \\
\hline 32 & 7.83 & 0.178 & 754 & 771 & -1.91 \\
\hline 47 & 10.00 & 0.189 & 782 & 801 & 1.88 \\
\hline 63 & 10.00 & 0.182 & 805 & 825 & 4.93 \\
\hline \multicolumn{6}{|c|}{ Case E: OL-FCA with WDGs (15\% penetration); Fig.10(b) } \\
\hline 16 & 7.65 & 0.160 & 714 & 730 & -7.14 \\
\hline 32 & 7.78 & 0.160 & 738 & 755 & -3.97 \\
\hline 47 & 10.04 & 0.160 & 753 & 771 & -1.93 \\
\hline 63 & 9.78 & 0.172 & 778 & 797 & 1.37 \\
\hline
\end{tabular}

*) Excluding WDGs.

**) Percentage of nominal cost with no PEVs, exculding WDG cost.

TABLE III

CASE G: IMPACT OF CHANGING WDG PENETRATION ON SMART GRID SYSTEM OF FIG.5 WITH 63\% PEV PENETRATION AND OL-FCA COORDINATION.

\begin{tabular}{|c|c|c|c|c|c|}
\hline $\begin{array}{c}\text { WDG } \\
{[\mathbf{\%}]^{*}}\end{array}$ & $\begin{array}{c}\Delta \boldsymbol{V} \\
{[\%]}\end{array}$ & $\begin{array}{c}\text { Total Power } \\
\text { Loss } \\
{[\mathbf{M W / d a y}]}\end{array}$ & $\begin{array}{c}\text { Generation } \\
\text { cost } \\
{[\mathbf{\$} / \mathbf{d a y}]}\end{array}$ & $\begin{array}{c}\text { Total cost } \\
\mathbf{( E q . 1 )} \\
{[\mathbf{\$} / \mathbf{d a y}]}\end{array}$ & $\begin{array}{c}\text { Increase in Total } \\
\text { cost [\%] }\end{array}$ \\
\hline 5 & 9.70 & 0.2093 & 838 & 858 & 9.13 \\
\hline 10 & 9.74 & 0.2078 & 808 & 827 & 5.19 \\
\hline 15 & 9.78 & 0.2065 & 781 & 801 & 1.88 \\
\hline 20 & 9.87 & 0.2053 & 753 & 772 & -1.81 \\
\hline 30 & 9.96 & 0.2031 & 696 & 715 & -9.05 \\
\hline 40 & 10.05 & 0.2012 & 639 & 658 & -16.30 \\
\hline
\end{tabular}

**) Percentage of nominal generation with no PEVs.

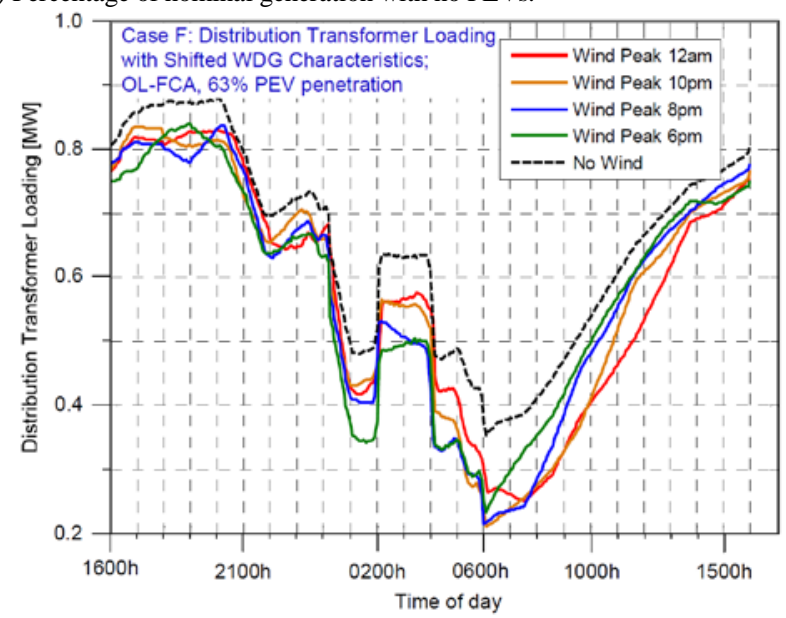

Fig. 11. Case F: Impact of WDG peak generation time on distribution transformer loading (OL-FCA coordination, 63\% PEV penetration). 


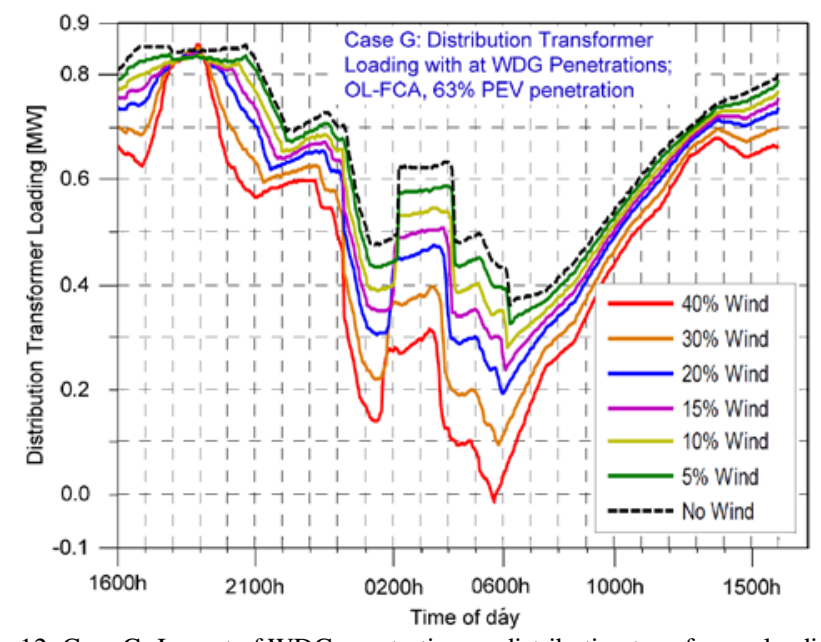

Fig. 12. Case G: Impact of WDG penetration on distribution transformer loading (OL-FCA coordination, 63\% PEV penetration, WDG peak generation at 6pm).

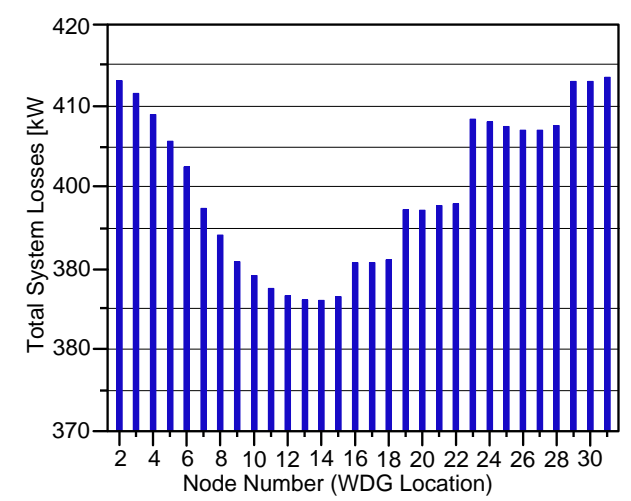

Fig. 13. Case G: Impact of WDG location on total system losses (63\% PEV penetration with one $21 \mathrm{~kW}$ WDG connected at different nodes).

\section{CONCLUSION}

This paper proposes a fast and simple online fuzzy coordination algorithm (OL-FCA) for charging PEV batteries based on MSS optimization and fuzzy reasoning. It is implemented on a 449-node $23 \mathrm{kV}$ test system consisting of 22 low voltage residential networks populated with PEVs. OL-FCA has the following advantages and capabilities:

- Compared to MSS coordinated PEV charging of [12], it offer further improvements in terms of loss and cost reduction.

- It takes advantage of DG resources by utilizing their output powers particularly during peak DG generation periods to service more vehicles and reduce the total cost.

- It does not require forecasting of PEVs and/or DGs as the information on random arrivals of vehicles and the intermittent outputs/status renewable resources are updated online through the smart meters.

- It provides consumer charging time zones based on priority, regulates node voltages and controls system peak demand while improving the efficiency and economy of smart grid by reducing cost of energy generation.

- It will also reduce the burden on substation and local distribution transformers and circuits that will minimize the risk and cost of premature equipment failures and associated outages.
The main improvements of OL-FCA compared with the MSS algorithm of [11-12] are application of fuzzy theory to increase the possibility of capturing a better local solution and the reduction in the total cost (over $2.5 \%$; Table II, rows 12 13 and 17-18) particularly at high penetrations of PEVs.

The fuzzy set theory is used to properly combine the objective function (Eq.1) and constraints (Eqs.2-3). Therefore, the quality of solution and convergence characteristic of OL-FCA are the same as the MSS technique [11-12, 26]. However, application of fuzzy theory increases the possibility of capturing a better local solution.

To improve the solution, near global optimization techniques with more computational efforts such as genetic algorithm (GA) [28], particle swarm optimization (PSO) [29], tabu search [30] may be considered. The authors are investigating the computation of near global PEV coordination solutions and hope to publish some results in the future.

\section{REFERENCES}

[1]. W. Su, H. Rahimi-Eichi, W. Zeng, M.Y. Chow, "A survey on the electrification of transportation in a smart grid environment", IEEE Transactions on Power Systems, Vol.3, No.1, pp.1-10, 2012.

[2]. X. Fang, S. Misra, G. Xue, D. Yang, "Smart grid- the new and improved power grid: A survey,” IEEE Communications Survey \& Tutorials, Vol.14, No.4, Fourth Quarter, pp.944-980, 2012.

[3]. M. Yilmaz, P.T. Krein, "Review of the impacts of vehicles-to-grid technologies on distribution systems and utility interfaces," IEEE Transactions on Power Electronics, Vol.28, No.12, pp.5673-5689, 2013.

[4]. L.P. Fernández, T.G.S. Román, R. Cossent, C.M. Domingo, P. Frías, "Assessment of the impact of plug-in electric vehicles on distribution networks", IEEE Transactions on Smart Grid, Vol.26, No.1, pp.206-213, 2011.

[5]. E. Sortomme, M.M. Hindi, S.D.J. MacPherson, S.S.Venkata, "Coordinated charging of plug-in hybrid electric vehicles to minimize distribution system losses”, IEEE Transactions Smart Grid, Vol.2, No.1, pp.198-205, 2011.

[6]. K. Clement-Nyns, E. Haesen, and J. Driesen, "The impact of charging plugin hybrid electric vehicles on a residential distribution grid", IEEE Transactions on Power Systems, Vol.25, No.1, pp. 371-380, 2010.

[7]. M. Zhongjing, D.S. Callaway, I.A. Hiskens, "Decentralized charging control of large populations of plug-in electric vehicles," IEEE Transactions on Control Systems Technology, Vol.21, No.1, pp.67-78, 2013.

[8]. S. Vandael, B. Claessens, M. Hommelberg, T. Holvoet, G. Deconinck, “A scalable three-step approach for demand side management of plug-in hybrid vehicles," IEEE Transactions on Smart Grid, Vol.4, No.2, pp.720-728, 2013.

[9]. C. Jin, J. Tang, P. Ghosh, "Optimizing electric vehicle charging: A customer's perspective," IEEE Transactions on Vehicular Technology, Vol.62, No.7, pp.2919-2927, 2013.

[10]. J.M. Foster, M.C. Caramanis, "Optimal power market participation of plug-in vehicles pooled by distribution feeder," IEEE Transactions on Power Systems, Vol.28, No.3, pp.2065-2076, 2013.

[11]. Amir S. Masoum, S. Deilami, P.S. Moses, M.A.S. Masoum, A. AbuSiada, "Smart load management of plug-in electric vehicles in distribution and residential networks with charging stations for peak shaving and loss minimization considering voltage regulation”, IET Proceedings on Generation, Transmission and Distribution, Vol.5, No.8, pp.877-888, 2011.

[12]. S. Deilami, A.S. Masoum, P.S. Moses, M.A.S. Masoum, "Real-time coordination of plug-in electric vehicle charging in smart grids to minimize power losses and improve voltage profile”, IEEE Transactions on Smart Grid, Vol.2, No.3, pp.456-467, 2011.

[13]. D. Wu, D.C. Aliprantis, L. Ying, "Load scheduling and dispatch for aggregators of plug-in electric vehicles", IEEE Transactions on Smart Grid, Vol.3, No.1, pp.368-376, 2012.

[14]. A. Ashtari,, E. Bibeau, S. Shahidinejad, T. Molinski, "PEV charging profile prediction and analysis based on vehicle usage data", IEEE Transactions on Smart Grid, Vol.3, No.1, pp.341-350, 2012.

[15]. B. Geng, J.K. Mills, D. Sun, "Two-stage charging strategy for plug-in electric vehicles at the residential transformer level," IEEE Transactions on Smart Grid, Vol 4, No.3, pp.1442-1452, 2013. 
[16]. J. Linni, X. Honghong, X. Guoqing, Z. Xinyu, Z. Dongfang, Z.Y. Shao, "Regulated charging of plug-in hybrid electric vehicles for minimizing load variance in household smart microgrid," IEEE Transactions on Industrial Electronics, Vol.60, No.8, pp.3218-3226, 2013.

[17]. L. Gan, U. Topcu, S. Low, "Optimal decentralized protocol for electric vehicle charging," IEEE Transactions on Power Systems, Vol.28, No.2, pp.940-951, 2013.

[18]. N. Rotering M. Ilic, "Optimal charge control of plug-in hybrid electric vehicles in deregulated electricity markets," IEEE Transactions on Power Systems, Vol.26, No.3, pp.1021-1029, 2011.

[19]. S. Deilami, A.S. Masoum, P.S. Moses, M.A.S. Masoum, "Voltage profile and THD distortion of residential network with high penetration of plug-in electrical vehicles”, IEEE ISGT Europe 2010 Conference, Gothenburg, Sweden, October 10-13, 2010.

[20]. P. Richardson, D. Flynn, A. Keane, "Optimal charging of electric vehicles in low-voltage distribution systems," IEEE Transactions on Power Systems, Vol.27, No.1, pp.268-279, 2012.

[21]. S. Bashash, H.K. Fathy, “Transport-based load modeling and sliding mode control of plug-in electric vehicles for robust renewable power tracking”, IEEE Transactions on Smart Grid, Vol.3, No.1, pp.526-534, 2012.

[22]. J M. Falahi, C. Hung-Ming Chou, M. Ehsani, X. Le. K.L. Butler-Purry, "Potential power quality benefits of electric vehicles", IEEE Transactions on Sustainable Energy, Vol.2, No.1, pp. 1016-1023, 2013.

[23]. J.R. Pillai, B. Bak-Jensen, "Integration of vehicle-to-grid in the Western Danish power system”, IEEE Transactions on Sustainable Energy, Vol.2, No.1, pp. 12-19, 2011

[24]. W. Hu, C. Su, Z. Chen, B. Bak-Jensen, “Optimal operation of plug-in electric vehicles in power systems with high wind power penetrations”, IEEE Transactions on Sustainable Energy, Vol.2, No.1, pp. 577-585, 2013.

[25]. S.Y. Derakhshandeh, A.S. Masoum, S. Deilami, M.A.S. Masoum, M.E.H. Golshan, "Coordination of generation scheduling with PEVs charging in industrial microgrids”, IEEE Transactions on Power Systems, Vol.28, No.3, pp.3451-4361, 2013.

[26]. M.A.S. Masoum, A. Jafarian, M. Ladjevardi, E.F. Fuchs, W.M. Grady, "Fuzzy approach for optimal placement and sizing of capacitor banks in the presence of harmonics”, IEEE Transactions on Power Delivery, Vol.19, No.2, pp.822-829, 2004.

[27]. G. Deschrijver, “Additive and multiplicative generators in interval-valued fuzzy set theory”, IEEE Transactions on Fuzzy Systems, Vol.15, No.2, pp.222237, 2007.

[28]. A. Ulinuha, M.A.S. Masoum, S.M. Islam, "Hybrid genetic-fuzzy algorithm for Volt/Var/THD control of distribution systems with high penetration of nonlinear loads", IET Proceedings on Generation, Transmission and Distribution, Vol.5, No.4, pp.425-439, 2011.

[29]. S. Hajforoosh, S.M.H. Nabavi, M.A.S. Masoum, “Coordinated aggregatedbased particle swarm optimization algorithm for congestion management in restructured power market by placement and sizing of unified power flow controller”, IET Proceedings on Science, Measurement \& Technology, Vol.6, No.4, pp.267-278, 2012.

[30]. B.R. Pereira Junior, A.M. Cossi, J. Contreras, J.R.S. Mantovani, "Multiobjective multistage distribution system planning using tabu search", IET Proceedings on Generation, Transmission and Distribution,Vol.8, No.1, pp.35-45, 2014.
Amir S. Masoum received his B.S. and M.S. degrees in Electrical Engineering and Electrical Utility Engineering from the University of Western Australia, WA, Australia, and Curtin University, WA, Australia in 2009 and 2010 , respectively. He has been a Project Manager at the Operational Asset Management, Western Power, WA, Australia since 2010 and is currently working towards a $\mathrm{PhD}$ degree in Electrical Engineering at Curtin University, WA, Australia.

Sara Deilami received her B.S. and M.S. degrees in Electrical Engineering from Islamic Azad University, Tehran, Iran and Curtin University, WA, Australia in 2000 and 2011, respectively. She was awarded a Curtin University Postgraduate Scholarship (CUPS) and an Australian Postgraduate Award (APA) scholarship in 2010 and 2011, respectively. She has nine years of industry experience. Currently, she is a Faculty Member at the Electrical and Computer Engineering Department, Curtin University, Perth, WA, Australia.

A. Abu-Siada (M’07, SM'12) received his B.Sc. and M.Sc. degrees from Ain Shams University, Egypt and the PhD degree from Curtin University of Technology, Australia, All in Electrical Engineering. Currently, he is a senior lecturer at the Department of Electrical and Computer Engineering, Curtin University. His research interests include power system stability, condition monitoring, power electronics, power quality and energy technology.

Mohammad A.S. Masoum (S'88-M'91-SM'05) received his B.S., M.S. and $\mathrm{PhD}$ degrees in Electrical and Computer Engineering in 1983, 1985, and 1991, respectively, from the University of Colorado at Boulder, USA. Currently, he is a Professor and the discipline leader for Power System Engineering at the Electrical and Computer Engineering Department, Curtin University, Perth, Australia. Dr. Masoum is the co-author of "Power Quality in Power Systems and Electrical Machines" (Elsevier, 2008) and "Power Conversion of Renewable Energy Systems” (Springer, 2011). 